\title{
Postoperative pain after spinal surgery in the paediatric population
}

\author{
Barbara K. Kościelniak-Merak ${ }^{1}$, Ilona Batko², Krzysztof Kobylarzz ${ }^{2,3}$, Przemysław J. Tomasik ${ }^{1}$ \\ ${ }^{1}$ Department of Clinical Biochemistry, Pediatrics Institute, Jagiellonian University Medical College, \\ Cracow, Poland \\ 2University Children's Hospital, Faculty of Medicine, Jagiellonian University, Cracow, Poland \\ ${ }^{3}$ Department of Anaesthesiology and Intensive Care, Jagiellonian University Medical College, \\ Cracow, Poland
}

\begin{abstract}
Background: Postoperative pain is a major after-effect of surgery. Especially severe pain occurs after extensive operations on the spine. The goal of the study was to investigate the laboratory predictive factors of intense postoperative pain in children undergoing extensive surgery

Methods: We recruited 41 children, median age 13 years (IQR: 10-15 years) undergoing extensive spinal surgery. The subjects were divided into two groups based on the intensity of postoperative pain measured using the 10-point numerical rating scale (NRS), visual analogue scale (VAS) or Faces Pain Scale-Revised (FPS-R). Patients with a score of 5 or higher were included in the study group while those with an NRS score of less than 5 were included in the control group. We collected detailed clinical and laboratory data before, during and after surgery.

Results: The highest intensity of pain was observed in the first 6 hours after surgery. Postoperative pain was associated with a greater drop in the haemoglobin concentration and haematocrit level in the peri-operative period $(P=0.006$ and $P=0.019$, respectively), as well as increases in mean arterial pressure during surgery. Additionally, we found that children with intense pain had a higher total protein concentration after surgery.

Conclusions: We reported that the decrease in haemoglobin and haematocrit levels, fluctuations in mean arterial pressure, as well as the total protein concentration, could be useful prognostic factors of early postoperative pain.
\end{abstract}

Anaesthesiology Intensive Therapy 2018, vol. 50, no 4, 252-258

Key words: children; surgery, spine; pain, postoperative; pain, intensity

Postoperative pain is one of the most common and most complained about after-effects of surgery [1, 2]. One's perceived intensity of pain heavily depends on the location and extent of surgery. Especially severe pain occurs after extensive surgery on the spine [2]. Effective pain relief in the peri- and postoperative period will certainly improve patient's overall well-being [3]. Moreover, it may also reduce the number of complications and shorten the time of hospitalisation. The development of safer, more effective analgesics for the management of postoperative pain requires a better understanding of the mechanisms of tissue injury-induced acute pain. Several authors have analysed the predictive factors of the severity of postoperative pain and highlighted the following elements: female gender; younger age; type of surgery; incision length; severity of preoperative pain; use of analgesics before surgery; psychological background; and genetic characteristics [2-4]. Up to date, there have been no studies correlating the results of laboratory parameters with postoperative pain intensity. Routine laboratory tests could provid easily obtainable predictive factors of the intensity of postoperative pain in children after extensive spinal surgery and may be helpful in both anticipating the patient's needs and prescribing well-targeted analgesia. The purpose of this study was to identify the clinical and laboratory factors associated with postoperative pain following extensive spinal surgery in children. 


\section{METHODS}

\section{PARTICIPANTS}

The University Ethical Committee approved the study and written parental informed consent, as well as the child's assent, were obtained for all participants upon enrolment in the study.

Children of both sexes with significant disorders in the structure of the anatomy of the spine qualified to undergo extensive surgical and reconstructive procedures were recruited. The exclusion criteria were as follows: an ASA score above 2; a patient with severe systemic disease that is a constant threat to life or a moribund patient who is not expected to survive without an operation; allergy to local anaesthetics; chronic opioid therapy; organ transplants in one's medical history; a body mass index percentile adjusted for the child's age and sex (BMI percentile) $\geq 95$. As a baseline study, investigators collected data on demographic characteristics, comorbidities, medications and routine laboratory findings.

\section{SURGICAL PROCEDURES}

Thirty minutes before incision, dexamethasone (0.1 $\mathrm{mg} \mathrm{kg}^{-1}$ ) and paracetamol ( $\left.15 \mathrm{mg} \mathrm{kg}^{-1}\right)$ were administered. During the induction of general anaesthesia, the following agents were employed: fentanyl $1 \mu \mathrm{g} \mathrm{kg}^{-1}$; propofol $2 \mathrm{mg} \mathrm{kg}^{-1}$ or thiopental $5 \mathrm{mg} \mathrm{kg}^{-1}$; and rocuronium 0.6 $\mathrm{mg} \mathrm{kg}^{-1}$. The children were intubated using a reinforced ("armored") endotracheal tube. To maintain anaesthesia, the following agents were employed: sevoflurane and oxygen/air or fentanyl; rocuronium; morphine; and metamizole. Sugammadex ( 2 to $4 \mathrm{mg} \mathrm{kg}^{-1}$ ) was used as a reversal agent for neuromuscular block. Direct measurements were taken of arterial pressure, body temperature, as well as sleep depth evaluated by the bispectral index (BIS). Moreover, ventilatory and haemodynamic parameters were monitored. Particular attention was paid to optimal body positioning, protection against ocular hypertension, the prevention of hypothermia, an appropriate waterelectrolyte balance, adequate replenishment of blood loss, efficient analgesic and antifibrinolytic treatment, perioperative antibiotic therapy, and the prevention, early detection, and treatment of complications. Following the completion of the surgical procedure, the patient was recovered from anaesthesia in a standard manner and extubated on the operating table and subsequently transported to the Intensive Care Unit (ICU), where they remained until their general condition stabilised. The principal analgesic was morphine during the first $48 \mathrm{~h}$ after surgery, administered as a PCA (patient-controlled analgesia) which was programmed to deliver $1 \mathrm{mg}$ of morphine with a lockout interval of 10 minutes. The 4-hour dose limit was $0.3 \mathrm{mg} \mathrm{kg}^{-1}$. Additionally, we employed non-opioid analgesic drugs, namely: metamizole and paracetamol.

\section{LABORATORY DETERMINATIONS}

Routinely, an arterial line was inserted. The complete blood count, coagulology parameters, arterial blood gases, electrolytes, lactate, glucose concentration, albumin, as well as total protein concentration, were determined preoperatively, during surgery and immediately after surgery.

\section{PAIN INTENSITY MEASUREMENTS}

Pain intensity was assessed using the visual analogue scale (VAS), Faces Pain Scale-Revised (FPS-R) or numerical rating scale (NRS) where 0 means no pain, and 10 means the maximum level of pain which the patient can imagine. Qualified nursing-medical staff evaluated the intensity of the pain at baseline ( 0 hours) and at postoperative hours $2,6,9,15,24,30,40$ and 48 after the operation. Scores of 5 or greater indicated severe postoperative pain. The study group included children with one of the following pain intensity patterns within the first 48 postoperative hours during rest and movement: early postoperative pain $\geq 5$ as assessed on the rating scale; early postoperative pain from 3 to 5 and progressing in intensity despite analgesic use; and no early postoperative pain (under 3 ) but progressing in intensity. The remaining patients from the study cohort were included in the control group without matching of patient characteristics.

\section{STATISTICAL ANALYSIS}

Allcalculationswere performed withSTATISTICAv.12,(StatSoft Inc., Tulsa, USA). Categorical variables were presented as numbers and percentages; continuous variables were expressed as a mean \pm standard deviation or as a median and interquartile range (IQR). Differences between groups were compared using Student's or Welch's t-test depending on the equality of variances for normally distributed variables. The Mann-Whitney U test was used for non-normally distributed continuous variables. Normality was assessed by the Shapiro-Wilk test in each group. Categorical variables were compared by Fisher's exact test. Moreover, the Spearman or Pearson correlations coefficients were calculated in order to measure the linear dependence between two variables. The significance level in all analyses was set at $P=0.05$.

\section{RESULTS}

The study group (children with moderate to severe pain) included 21 children of both genders (14 girls, 67\%), with a median age of 13 years (IQR: 10.5-14 years). The average 
Table 1. Study variables between case and control subjects

\begin{tabular}{|c|c|c|c|}
\hline Variable & Control $(n=20)$ & Cases $(\mathrm{n}=21)$ & $P$-value \\
\hline Age, years & $12(7-15)$ & $13(10.5-14)$ & 0.062 \\
\hline Female, n (\%) & $12(60)$ & $14(67)$ & 0.411 \\
\hline SDS-BMI, $\mathrm{kg} \mathrm{m}^{-2}$ & $19.1 \pm 3.0$ & $18.4 \pm 2.6$ & 0.086 \\
\hline \multicolumn{4}{|l|}{ Cause of the surgery } \\
\hline correction of scoliosis & $10(50)$ & $12(58)$ & 0.514 \\
\hline reduction of spondylolisthesis & $2(10)$ & $1(5)$ & 0.876 \\
\hline exchange of implantable devices & $2(10)$ & $2(9)$ & 0.998 \\
\hline correction of hyperkyphosis & $2(10)$ & $2(9)$ & 0.978 \\
\hline vertebral fracture & $1(5)$ & $2(9)$ & 0.763 \\
\hline tumour in the vertebra/s & $2(10)$ & $1(5)$ & 0.659 \\
\hline semicircular canal resection & $1(5)$ & $1(5)$ & 0.965 \\
\hline \multicolumn{4}{|l|}{ Operative part of the spine } \\
\hline cervical & $2(10)$ & $1(5)$ & 0.743 \\
\hline thoracic & $1(5)$ & $4(19)$ & 0.431 \\
\hline thoracic and lumbar & $16(80)$ & $14(67)$ & 0.688 \\
\hline lumbar and sacrum & $1(5)$ & $2(9)$ & 0.439 \\
\hline \multicolumn{4}{|l|}{ Perioperative data } \\
\hline previous spinal surgery, $\mathrm{n}(\%)$ & $9(47)$ & $7(58)$ & 0.411 \\
\hline morphine, $\mathrm{mg} \mathrm{kg}^{-1}$ & $0.90 \pm 0.48$ & $1.08 \pm 0.43$ & 0.068 \\
\hline fentanyl, $\mu \mathrm{g} \mathrm{kg}^{-1} \mathrm{~h}^{-1}$ & $1.63 \pm 0.63$ & $1.56 \pm 0.54$ & 0.076 \\
\hline intraoperative dopamine, $\mathrm{n}(\%)$ & $1(5)$ & $0(0)$ & 0.639 \\
\hline vertebrae undergoing surgery & $10 \pm 4$ & $11 \pm 4$ & 0.876 \\
\hline surgery duration, min & $273 \pm 101$ & $257 \pm 73$ & 0.655 \\
\hline analgesia duration, $\min$ & $348 \pm 116$ & $319 \pm 71$ & 0.453 \\
\hline average BIS, & $48.9 \pm 5.0$ & $48.0 \pm 4.5$ & 0.645 \\
\hline average end tidal sevoflurane concentration, $\%$ & $1.97 \pm 0,27$ & $1.99 \pm 0.22$ & 0.874 \\
\hline average heart rate, bpm & $82.5 \pm 15$ & $82 \pm 11$ & 0.095 \\
\hline mean arterial pressure, $\mathrm{mm} \mathrm{Hg}$ & $67.5 \pm 7.3$ & $66 \pm 5.3$ & 0.544 \\
\hline$\triangle \mathrm{MAP}, \mathrm{mm} \mathrm{Hg}$ & 8.1 & 11.3 & 0.046 \\
\hline $\mathrm{RCC}, \mathrm{mL} \mathrm{kg}{ }^{-1}$ & $21.25(12.4-28.7)$ & $19.1(9.2-23.9)$ & 0.094 \\
\hline $\mathrm{FFP}, \mathrm{mL} \mathrm{kg}{ }^{-1}$ & $15.58(11.4-20.4)$ & $9.7(4.9-19.1)$ & 0.023 \\
\hline RCC:FFP ratio & $1.30(0.85-1.68)$ & $1.96(1.56-2.25)$ & 0.029 \\
\hline intraoperative crystalloids, $\mathrm{mL} \mathrm{kg}^{-1}$ & $52.1(38.8-60.7)$ & $47.1(35.3-61.9)$ & 0.971 \\
\hline intraoperative colloids, $\mathrm{mL} \mathrm{kg}^{-1}$ & $18.6(12.2-22.1)$ & $11.2(6.4-15.2)$ & 0.091 \\
\hline \multicolumn{4}{|l|}{ Postoperative complications } \\
\hline respiratory depression & $2(10)$ & $2(9)$ & 0.978 \\
\hline bleeding & $1(5)$ & $2(9)$ & 0.773 \\
\hline pneumonia & 0 & $2(9)$ & 0.421 \\
\hline paresis of upper and lower limbs & 0 & $1(5)$ & 0.639 \\
\hline chronic pain & 0 & 0 & 1.0 \\
\hline \multicolumn{4}{|l|}{ Laboratory parameters before surgery } \\
\hline haemoglobin, $\mathrm{g} \mathrm{dL}^{-1}$ & $13.5 \pm 0.9$ & $13.4 \pm 0.7$ & 0.27 \\
\hline haematocrit, $\%$ & $40.8 \pm 3.6$ & $41.6 \pm 2.5$ & 0.46 \\
\hline white blood cells, G L-1 & $8.4 \pm 4.4$ & $8.8 \pm 3.1$ & 0.61 \\
\hline platelets, $\mathrm{G} \mathrm{L}^{-1}$ & $276 \pm 71$ & $289 \pm 105.5$ & 0.92 \\
\hline aPTT, sec. & $33.1 \pm 4.0$ & $33.5 \pm 2.8$ & 0.80 \\
\hline INR & $1.01 \pm 0.11$ & $1.11 \pm 0.06$ & 0.82 \\
\hline
\end{tabular}


Table $1 \mathrm{~cd}$. Study variables between case and control subjects

\begin{tabular}{|c|c|c|c|}
\hline Variable & Control $(n=20)$ & Cases $(n=21)$ & $P$-value \\
\hline \multicolumn{4}{|c|}{ Laboratory parameters during surgery } \\
\hline haemoglobin, $\mathrm{g} \mathrm{dL}^{-1}$ & $12.9 \pm 0.7$ & $8.7 \pm 1.2$ & 0.004 \\
\hline haematocrit, $\%$ & $34.2 \pm 2.4$ & $29.1 \pm 3.4$ & 0.007 \\
\hline $\mathrm{pH}$ & $7.44 \pm 0.05$ & $7.41 \pm 0.02$ & 0.11 \\
\hline $\mathrm{pCO}_{2}, \mathrm{~mm} \mathrm{Hg}$ & $39.5 \pm 4.2$ & $38.6 \pm 4.9$ & 0.35 \\
\hline $\mathrm{pO}_{2}, \mathrm{~mm} \mathrm{Hg}$ & $216 \pm 27$ & $208 \pm 22$ & 0.84 \\
\hline $\mathrm{BE}, \mathrm{mEq} \mathrm{L}^{-1}$ & $0.9 \pm 3.5$ & $0.01 \pm 2.88$ & 0.65 \\
\hline lactate, $\mathrm{mmol} \mathrm{L}^{-1}$ & $1.68 \pm 0.65$ & $1.74 \pm 0.59$ & 0.49 \\
\hline glucose, $\mathrm{mmol} \mathrm{L}^{-1}$ & $6.7 \pm 1.1$ & $6.8 \pm 1.1$ & 0.77 \\
\hline $\mathrm{Ca}^{2+}, \mathrm{mmol} \mathrm{L}^{-1}$ & $1.13 \pm 0.12$ & $1.18 \pm 0.04$ & 0.35 \\
\hline $\mathrm{Na}^{+}, \mathrm{mmol} \mathrm{L}^{-1}$ & $134 \pm 2$ & $139 \pm 2.5$ & 0.07 \\
\hline $\mathrm{K}^{+}, \mathrm{mmol} \mathrm{L}^{-1}$ & $4.0 \pm 1.1$ & $3.65 \pm 0.3$ & 0.05 \\
\hline \multicolumn{4}{|c|}{ Laboratory parameters immediately after surgery } \\
\hline haemoglobin, $\mathrm{g} \mathrm{dL}^{-1}$ & $13.3 \pm 1.7$ & $10.55 \pm 0.7$ & 0.014 \\
\hline haematocrit, $\%$ & $38.5 \pm 4.8$ & $33.1 \pm 2.6$ & 0.042 \\
\hline white blood cells, $\mathrm{GL}^{-1}$ & $16.6 \pm 5.0$ & $18.65 \pm 5.1$ & 0.31 \\
\hline reticulocytes, $\%$ & $0.01 \pm 0.003$ & $0.02 \pm 0.001$ & 0.75 \\
\hline platelets, G L-1 & $204 \pm 56$ & $211.5 \pm 59$ & 0.81 \\
\hline aPTT, sec & $35.1 \pm 7.4$ & $29.2 \pm 3.1$ & 0.10 \\
\hline INR & $1.07 \pm 0.13$ & $1.14 \pm 0.05$ & 0.097 \\
\hline $\mathrm{pH}$ & $7.31 \pm 0.05$ & $7.32 \pm 4.61$ & 1.0 \\
\hline $\mathrm{pCO}_{2}, \mathrm{~mm} \mathrm{Hg}$ & $47.02 \pm 5.54$ & $46.71 \pm 4.61$ & 0.88 \\
\hline $\mathrm{pO}_{2^{\prime}} \mathrm{mm} \mathrm{Hg}$ & $132 \pm 43$ & $118 \pm 69.5$ & 0.33 \\
\hline $\mathrm{BE}, \mathrm{mEq} \mathrm{L}^{-1}$ & $-2.36 \pm 2.27$ & $-2.85 \pm 3.48$ & 0.78 \\
\hline lactate, $\mathrm{mmol} \mathrm{L}^{-1}$ & $2.25 \pm 1.25$ & $2.30 \pm 0.96$ & 0.65 \\
\hline glucose, $\mathrm{mmol} \mathrm{L}^{-1}$ & $8.34 \pm 2.21$ & $8.75 \pm 2.75$ & 0.95 \\
\hline $\mathrm{Ca}^{2+}, \mathrm{mmol} \mathrm{L}^{-1}$ & $1.18 \pm 0.05$ & $1.21 \pm 0.04$ & 0.29 \\
\hline $\mathrm{Na}^{+}, \mathrm{mmol} \mathrm{L}^{-1}$ & $139 \pm 3$ & $143 \pm 2.9$ & 0.12 \\
\hline $\mathrm{K}^{+}, \mathrm{mmol} \mathrm{L}^{-1}$ & $4.08 \pm 0.60$ & $3.85 \pm 0.56$ & 0.07 \\
\hline total protein, $\mathrm{g} \mathrm{L}^{-1}$ & $51.2 \pm 8.2$ & $58.6 \pm 4.9$ & 0.041 \\
\hline albumin, $\mathrm{g} \mathrm{L}^{-1}$ & $28.9 \pm 5.3$ & $31.5 \pm 3.2$ & 0.094 \\
\hline
\end{tabular}

Continuous variables are presented as a median (interquartile range) or a mean \pm standard deviation; BMI: body mass index; BIS: bispectral index; RCC: red cell concentrate; FFP: fresh frozen plasma; aPTT: activated partial thromboplastin time; INR: international normalized ratio; BE: base excess

SDS-body mass index was $18.4 \pm 2.6 \mathrm{~kg} \mathrm{~m}^{-2}$. The control group consisted of 20 children ( 12 girls, $60 \%$ ), with a median age of 12 years (IQR: 7-15 years). A demographic and clinical comparison between the study (more pain) and control groups (less pain) is presented in Table 1.

Pain intensity evaluated using the pain scale in both groups is shown in Figure 1. In our study, we observed that children with moderate and severe postoperative pain at rest and during movement had a lower concentration of haemoglobin and value of haematocrit immediately after surgery ( $P=0.005$ and $P=0.007$, respectively; Fig. 2$)$ when compared with the control group. The average drop before and during surgery in the haemoglobin concentration was $0.6 \mathrm{~g} \mathrm{dL}^{-1}$ in patients with mild pain and $4.7 \mathrm{~g} \mathrm{dL}^{-1}$ in children with moderate to severe pain $(P=0.006)$, while the average decrease in the haematocrit level was $6.6 \%$ and $16.7 \%$, respectively ( $P=0.019$ ) (Fig. 2 ). We found a positive correlation between pain intensity and a drop in the haematocrit level $(r=0.415 ; P=0.022)$, as well as between a drop in the haemoglobin concentration $(r=0.322 ; P=$ 0.041). We also observed that children with moderate to severe pain had a higher concentration of total protein (TP) immediately after surgery $(P=0.0004)$. Additionally, we reported a lower supply of intraoperative fresh frozen plasma (FFP), as well as a higher red cells concentrate (RCC) to FFP ratio in the study group when compared with the 
control group ( $P=0.047$ and $P=0.002$, respectively), while the administered volume of colloids and crystalloids was the same in both groups. Finally, we found that children with higher postoperative pain had higher drops in mean arterial pressure (MAP) during surgery when compared with the control group ( $P=0.04$; Fig 3). Moreover, we noted a positive correlation between $\triangle \mathrm{MAP}$ and pain intensity $(r=0.446 ; P=0.016)$. Finally, we did not note any significant differences between the groups in the remainder of the routinely measured laboratory parameters.

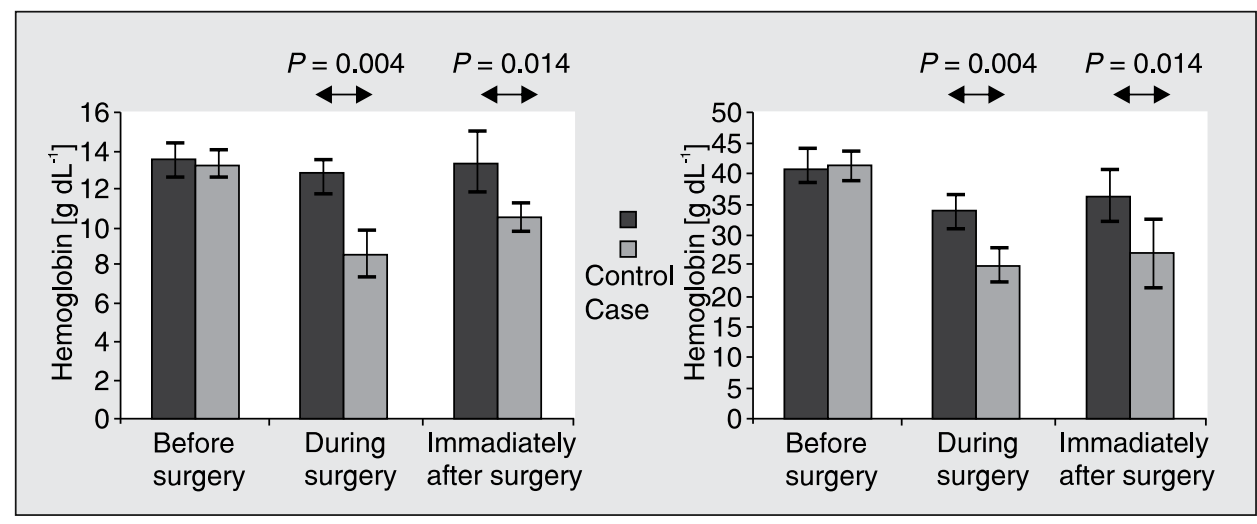

Figure 1. Pain intensity at the study hours between the groups at rest and during movement, as measured by NRS, VAS or FPS/R

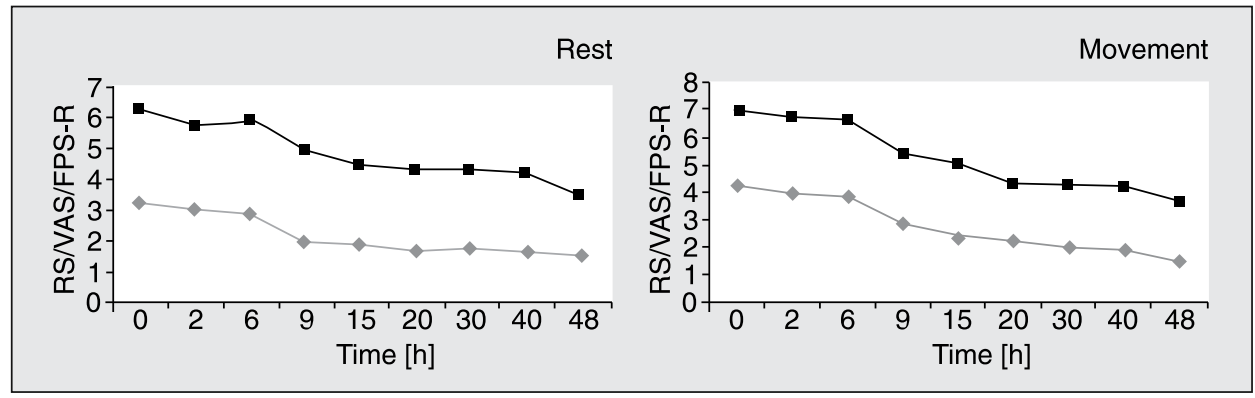

Figure 2. Haemoglobin concentration and haematocrit level between groups before, during and after surgery.

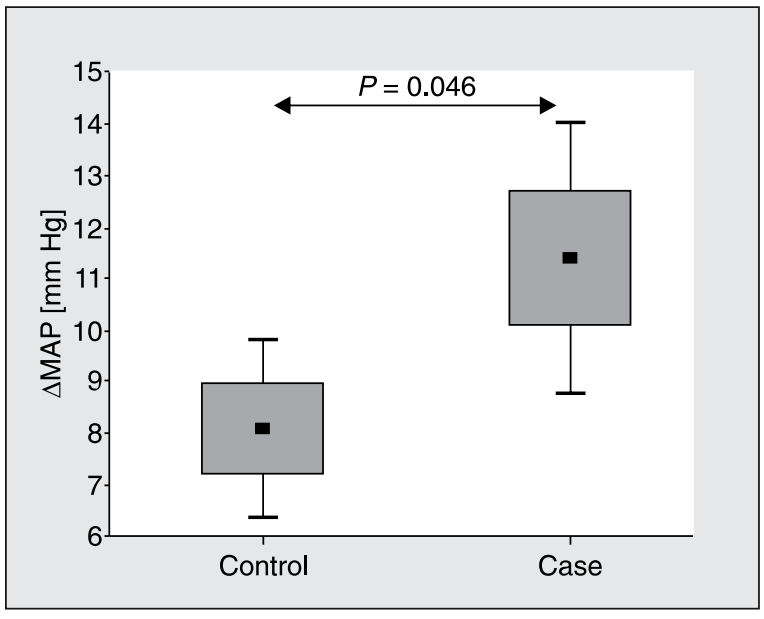

Figure 3. Comparison of $\triangle \mathrm{MAP}$ between groups. Middle point = mean value; box = standard error of the mean; bars = standard deviation

\section{DISCUSSION}

The ability to successfully counteract postoperative pain is crucial for faster recovery and shorter hospitalisation time. This is especially true for spinal operations, which are becoming more common and, at the same time, more complex $[5,6]$. Unfortunately, this is still an unsolved problem, especially in the paediatric population [7-9]. In our study, we analysed the correlation between routine, easy obtainable laboratory test results and pain intensity in the early postoperative period. We believe we have identified predictive factors that could prove very useful to clinicians, especially immediately after surgery, when the patient is not yet conscious. To the best of our knowledge, this study is the first to show the relationship between the intensity of pain and intraoperative routine laboratory blood tests in paediatric patients undergoing extensive spinal surgery. 
In the current study, we observed a significant decrease in both haemoglobin concentration and haematocrit levels in children with higher pain intensity. Simultaneously, we noted no statistically significant differences in platelet or leukocyte levels and other measured labolatory parameters, except total protein concentration. It has been previously shown that a decreased perioperative concentration of haemoglobin is a recognised factor that affects the length of hospitalisation, transfusion risk, morbidity, as well as mortality [10]. It has been shown that adult patients who experience a drop in haemoglobin in the postoperative period may have significantly reduced functional status [11]. Similarly, Dunne et al. [12] noticed increased mortality, risk of pneumonia and length of hospital stay among patients whose haematocrit levels had dropped to below 36\%, immediately after surgery. Moreover, Kougias et al. [13] reported that a haemoglobin level less than $10.0 \mathrm{~g} \mathrm{dL}^{-1}$ in the perioperative period is associated with an increased likelihood of wound infection in vascular surgery. Based on this, one may conclude that monitoring of haemoglobin and haematocrit levels in the perioperative period may be clinically useful in predicting factors of pain intensity in the postoperative period. A better understanding of preoperative pain indicators, therefore, could enable clinicians to develop more effective pain management.

Moreover, in the present study, we noted higher fluctuations in arterial blood pressure during surgery in the study group when compared with the control group. This could be caused by a multitude of factors, including intraoperative blood loss, fluid shifts, anaesthetic agents, as well as vasoactive drugs [14]. Walsh et al. [15] reported that MAP decreasing below $55 \mathrm{~mm} \mathrm{Hg}$ at any time during surgery may be associated with an adverse outcome [15]. We observed a positive correlation between $\triangle \mathrm{MAP}$ and pain intensity in the postoperative period. This suggests that using blood pressure fluctuations rather than blood pressure decrease alone could provide more accurate predictions.

In our study, although the patients with moderate and severe pain had a higher postoperative total protein concentration, this was still under the reference range. It may be connected with a higher concentration of acute phase protein and pain mediators. Postoperative pain after surgery is typically associated with a neuroendocrine stress response that is proportional to the severity of the injury [16]. One may hypothesise that the patients from the study group experienced intraoperative hypovolaemia. This may lead to fluid shifts caused by dysfunction of the vascular barrier due to surgical procedures [16]. The fluid crossing the barrier contains proteins close to plasma concentration, or even higher, as surgical manipulations may increase capillary protein permeability excessively [17]. The increasing concentration of pain mediators in the blood stream may be the reason for the more intense pain noted in the postoperative period.

We also noted that children with a smaller volume of FFP infusion reported more intense pain after surgery. We may suspect that intravascular volume deficits may be a factor predicting postoperative pain intensity. There is increasing evidence that fluid management influences a patient's outcome after surgery. Maharaj et al. [18] observed that rehydration decreased the severity of postoperative pain, and thereby the need for postoperative analgesia. The administration of fluids may dilute the concentration of pain mediators in blood and thereby decrease pain intensity. They noted that the intravenous administration of large volume of fluids may reduce the severity of pain, as well as the need for opioid and oral anaelgesics in the postoperative period [18]. Similar observations were reported by Yogendran et al. [19], who showed that a large volume of IV fluids decrease the need for morphine after surgery in adult patients. All in all, there seems to be significant evidence supporting the fact that postoperative fluid administration improves patients' postoperative outcome/well-being.

\section{LIMITATIONS}

In the opinion of the authors, the major limitation of the study lies in the small number of members in each of the study groups. This may lead to the underestimation of the possible association between variables (type II error). This and other possible similar limitations could be overcome by increasing the sample size, thereby improving the statistical power of the study. Moreover, the perioperative patient's outcome is influenced by a multiple of the factors. Finally, in the study, we concentrated only on routine, easy-to-obtain parameters in order to find possible prognostic factors of postoperative pain.

\section{CONCLUSIONS}

Screening of routine laboratory parameters as predictors of postoperative pain may be clinically helpful in a child patient's pain management. We reported that a drop in haemoglobin and haematocrit levels, $\triangle M A P$ as well as total protein concentration, could be useful prognostic factors of intense postoperative pain.

\section{ACKNOWLEDGEMENTS}

1. Source of funding: none.

2. Conflict of interest: none.

\section{References}

1. Ramsay MA. Acute postoperative pain management. Proc (Bayl Univ Med Cent). 2000; 13(3): 244-247, indexed in Pubmed: 16389390.

2. Chou R, Gordon DB, de Leon-Casasola OA, et al. Management of Postoperative Pain: A Clinical Practice Guideline From the American Pain Society, the American Society of Regional Anesthesia and Pain Medicine, and the American Society of Anesthesiologists' Committee 
on Regional Anesthesia, Executive Committee, and Administrative Council. J Pain. 2016; 17(2): 131-157, doi: 10.1016/j.jpain.2015.12.008, indexed in Pubmed: 26827847.

3. Ip HY, Abrishami A, Peng PWH, et al. Predictors of postoperative pain and analgesic consumption: a qualitative systematic review. Anesthesiology. 2009; 111(3): 657-677, doi: 10.1097/ALN.0b013e3181aae87a, indexed in Pubmed: 19672167.

4. Vigneault $L$, Turgeon AF, Côté $D$, et al. Perioperative intravenous lidocaine infusion for postoperative pain control: a meta-analysis of randomized controlled trials. Can J Anaesth. 2011; 58(1): 22-37, doi: 10.1007/s12630-010-9407-0, indexed in Pubmed: 21061107.

5. Kasliwal MK, Mahapatra AK. Surgery for spinal cord lipomas. Indian J Pediatr. 2007; 74(4): 357-362, indexed in Pubmed: 17476080.

6. Rutherford EE, Tarplett LJ, Davies EM, et al. Lumbar spine fusion and stabilization: hardware, techniques, and imaging appearances. Radiographics. 2007; 27(6): 1737-1749, doi: 10.1148/rg.276065205, indexed in Pubmed: 18025515.

7. Brasher C, Gafsous B, Dugue S, et al. Postoperative pain management in children and infants: an update. Paediatr Drugs. 2014; 16(2): 129-140, doi: 10.1007/s40272-013-0062-0, indexed in Pubmed: 24407716.

8. Bailey L, Sun J, Courtney M, et al. Improving postoperative tonsillectomy pain management in children--a double blinded randomised control trial of a patient analgesia information sheet. Int J Pediatr Otorhinolaryngol. 2015; 79(5): 732-739, doi: 10.1016/j.ijporl.2015.03.003, indexed in Pubmed: 25796293.

9. Sng QW, Taylor B, Liam JLw, et al. Postoperative pain management experiences among school-aged children: a qualitative study. J Clin Nurs. 2013; 22(7-8): 958-968, doi: 10.1111/jocn.12052, indexed in Pubmed: 23311588.

10. Sommer M, de Rijke JM, van Kleef M, et al. Predictors of acute postoperative pain after elective surgery. Clin J Pain. 2010; 26(2): 87-94, doi: 10.1097/AJP.0b013e3181b43d68, indexed in Pubmed: 20090433.

11. Guinn NR, Broomer BW, WhiteW, et al. Comparison of visually estimated blood loss with direct hemoglobin measurement in multilevel spine surgery. Transfusion. 2013; 53(11): 2790-2794, doi: 10.1111/trf.12119, indexed in Pubmed: 23438094.

12. Dunne JR, Malone D, Tracy JK, et al. Perioperative anemia: an independent risk factor for infection, mortality, and resource utilization in surgery. J Surg Res. 2002; 102(2): 237-244, doi: 10.1006/jsre.2001.6330, indexed in Pubmed: 11796024.
13. Kougias $\mathrm{P}$, Orcutt $\mathrm{S}, \mathrm{Pak} T$, et al. Impact of postoperative nadir hemoglobin and blood transfusion on outcomes after operations for atherosclerotic vascular disease. J Vasc Surg. 2013; 57(5): 1331-7; discussion, doi: 10.1016/j.jvs.2012.10.108, indexed in Pubmed: 23384496.

14. Kreimeier U. Pathophysiology of fluid imbalance. Crit Care. 2000; 4 Suppl 2: S3-S7, doi: 10.1186/cc968, indexed in Pubmed: 11255592

15. Walsh M, Devereaux PJ, Garg AX, et al. Relationship between intraoperative mean arterial pressure and clinical outcomes after noncardiac surgery: toward an empirical definition of hypotension. Anesthesiology. 2013; 119(3): 507-515, doi: 10.1097/ALN.0b013e3182a10e26, indexed in Pubmed: 23835589.

16. Beilin B, Shavit Y, Trabekin E, et al. The effects of postoperative pain management on immune response to surgery. Anesth Analg. 2003; 97(3): 822-827, indexed in Pubmed: 12933409.

17. Strunden MS, Heckel K, Goetz AE, et al. Perioperative fluid and volume management: physiological basis, tools and strategies. Ann Intensive Care. 2011; 1(1): 2, doi: 10.1186/2110-5820-1-2, indexed in Pubmed: 21906324.

18. Maharaj CH, Kallam SR, Malik A, et al. Preoperative intravenous fluid therapy decreases postoperative nausea and pain in high risk patients. Anesth Analg. 2005; 100(3): 675-82, table of contents, doi: 10.1213/01. ANE.0000148684.64286.36, indexed in Pubmed: 15728051.

19. Yogendran S, Asokumar B, Cheng DC, et al. A prospective randomized double-blinded study of the effect of intravenous fluid therapy on adverse outcomes on outpatient surgery. Anesth Analg. 1995; 80(4): 682-686, indexed in Pubmed: 7893018.

\section{Corresponding author}

Barbara Kościelniak-Merak

Department of Clinical Biochemistry, University Children's Hospital Jagiellonian University, Faculty of Medicine, Cracow, Poland Wielicka St 265, 30-663 Cracow, Poland

e-mail:b.k.koscielniak@gmail.com

Received: 9.10.2017

Accepted: 13.06 .2018 